\title{
Recovery of pneumonia in 27 discharged COVID-19 patients with positive virus detection
}

\author{
Jiazhen Zheng ${ }^{1 \#}$, Fengjuan Chen ${ }^{2 \#}$, Shuo $\mathrm{Han}^{3}$, Rui Zhou ${ }^{1}$, Furong Li ${ }^{1}$, Huamin Liu ${ }^{1}$, Jianyun $\mathrm{Lu}^{4}$, \\ Xianbo $\mathrm{Wu}^{1}$ \\ ${ }^{1}$ Department of Epidemiology, School of Public Health (Guangdong Provincial Key Laboratory of Tropical Disease Research), Southern Medical \\ University, Guangzhou, China; ${ }^{2}$ Department of Medical Administration, Guangzhou Eighth People's Hospital, Guangzhou, China; ${ }^{3}$ Department of \\ Radiology, School of Public Health (Guangdong Provincial Key Laboratory of Tropical Disease Research), Southern Medical University, Guangzhou, \\ China; ${ }^{4}$ Department of Infectious Disease Control and Prevention, Guangzhou Center for Disease Control and Prevention, Guangzhou, China
}

"These authors contributed equally to this work.

Correspondence to: Xianbo Wu, MD, PhD. Department of Epidemiology, School of Public Health (Guangdong Provincial Key Laboratory of Tropical Disease Research), Southern Medical University, Guangzhou 510515, China. Email: wuxb1010@smu.edu.cn; Dr. Jianyun Lu. Department of Infectious Disease Control and Prevention, Guangzhou Center for Disease Control and Prevention, Baiyun District Qi De Road, Guangzhou 510440, China. Email: 258506273@qq.com.

Submitted May 13, 2020. Accepted for publication Jun 01, 2020.

doi: 10.21037/qims-20-656

View this article at: http://dx.doi.org/10.21037/qims-20-656

\section{Introduction}

An outbreak caused by a novel human coronavirus, severe acute respiratory syndrome coronavirus 2 (SARS-CoV-2) was first detected in Wuhan in December 2019 (1), and has since spread within China and to other countries. As of May 19, 2020, more than four million confirmed cases and 315,131 deaths had been reported globally (2). Till now, many patients with COVID-19 have been clinically cured and discharged. However, multiple COVID-19 cases showed SARS-CoV-2 testing positive again in discharged patients [redetectable as positive (RP)], which led to many investigation on RP topic (3-5). Initially, there existed much knowledge gap in the clinical features and transmission risk of RP patients. A study on fifteen RP patients, conducted by Li et al., suggested that RP patients might haven't been fully recovered at readmission and need great attention (6). However, this result may have been over interpreted. Recently, a growing number of clinical evidences indicate that RP result may not represent infectious virus, and unlikely reflect reinfection $(7,8)$. To give a detailed description on the clinical course of post-discharged RP patients and thus further confirm the recovery of RP patients, we studied 285 adult patients with COVID-19 and acquired their clinical outcome during post-discharge surveillance with PCR results. By March 10, 27 (9.5\%) of 285 discharged patients were shown to be RP. Despite the presence of recurrent PCR positivity, most RP patients were asymptomatic and showed remission of pulmonary abnormalities at readmission.

\section{Case series presentation}

There were 285 adult patients with COVID-19 under our observation. All cases have met the discharge criteria at first discharge: absence of fever for at least 3 days, substantial improvement in both lungs in chest CT, clinical remission of respiratory symptoms, and two throat-swab samples negative for SARS-CoV-2 RNA obtained at least $24 \mathrm{~h}$ apart (9). During the post-discharge surveillance (within 15 days after discharge), 27 (9.5\%) patients were re-tested positive for SARS-CoV-2 by use of RT-PCR on samples from the respiratory tract. Chest CT were obtained within 2 days both before discharge and after readmission.

The median age of the $27 \mathrm{RP}$ patients was 44 [interquartile range (IQR): 35-62, ranging from 19-79] years old, and 12 (44.4\%) cases were men. Among 22 cases who 


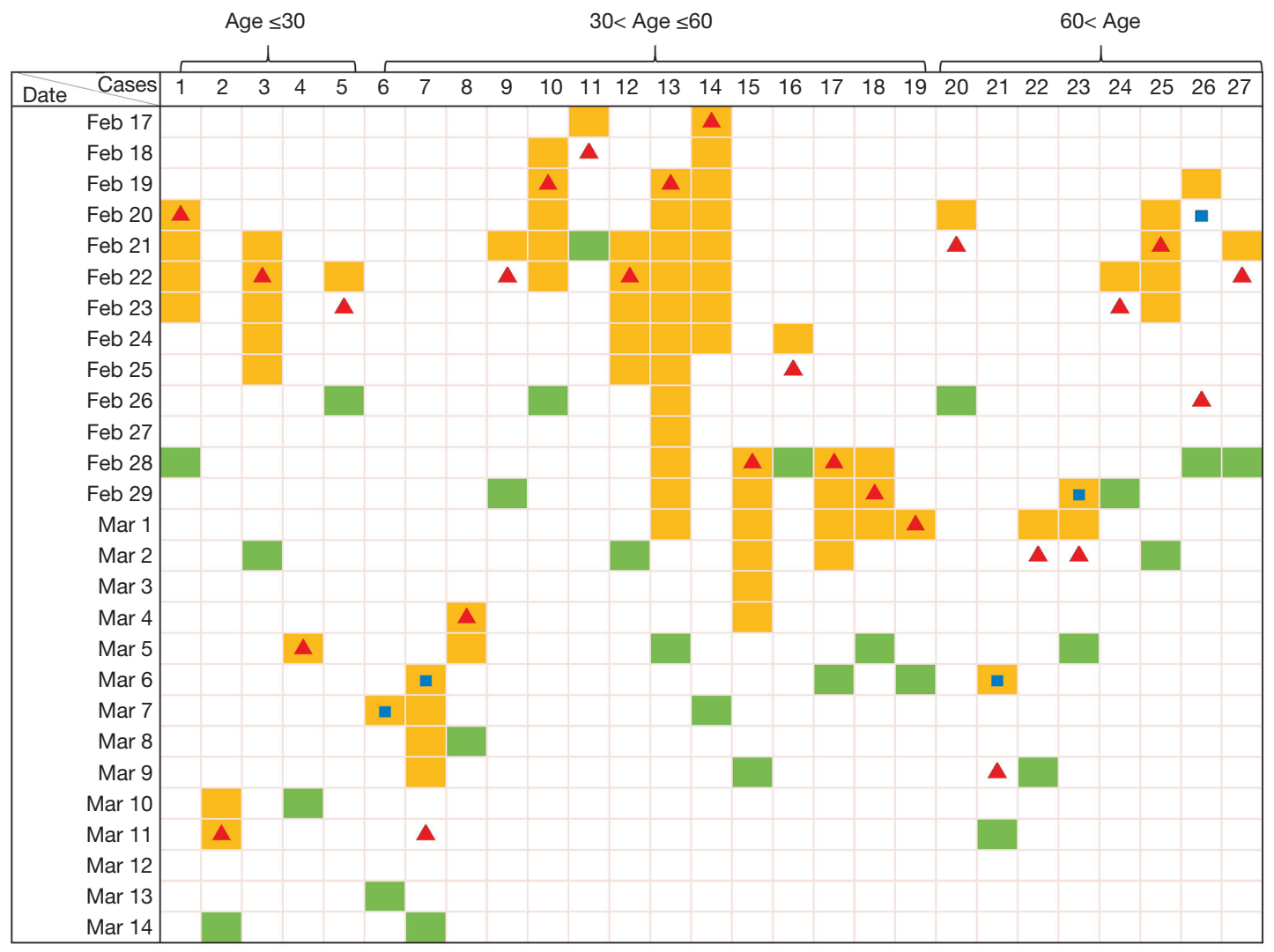

The duration of positive detection since readmission
Discharge
chest CT showed absorption of inflammation
chest CT showed persistent inflammation

Figure 1 Profile of 27 cases' viral shedding duration and chest CT scans in re-hospitalization.

remained clinically symptomatic at discharge, 17 (77.27\%) cases had symptoms resolvement at readmission. Specifically, 2/3 (66.7\%), 7/10 (70.0\%), 6/7 (85.7\%), 2/2 (100.0\%) cases had relief in fatigue, dry cough, chest distress and dizziness, respectively. During patients' rehospitalization, the median duration of viral shedding was 3 (IQR: 3-10, ranging from 1-12) days. Of those who underwent detection of the specific binding antibody to SARS-COV-2 in the plasma, 20 $(100.0 \%)$ and $16(80.0 \%)$ showed positivity of IgG and IgM, respectively. Compared with the CT at discharge, 21/24 $(87.5 \%)$ cases had resolvement of ground-glass opacities, $8 / 10(80.0 \%)$ had reduction in size of fibrotic streaks. One $(3.7 \%)$ case did not have abnormality in the lungs during both hospitalizations. Only 5/26 (19.2\%) cases showed no obvious change in pulmonary abnormality. None of the 17 cases showed pneumonia aggravation on chest CT. Cases appeared to demonstrate positive PCR result even after the absorption of pulmonary inflammation (Figure 1). The typical CT findings of RP patients were the resolvement of pulmonary inflammations at readmission. CT images obtained from five RP patients with different basic characteristics are shown in Figure 2.

\section{Discussion}

This is a report of a group of patients who were clinically cured and discharged but showed PCR positivity during post-discharge surveillance. In this study, most RP patients showed near-complete resolution of pulmonary CT abnormalities at re-admission, with no pulmonary reinfection occurred. Our results further confirm that RP patients are more likely to have false negative RT-PCR tests before discharging and the positive re-tests unlikely reflect reinfection (7). Since most RP patients can have pulmonary 

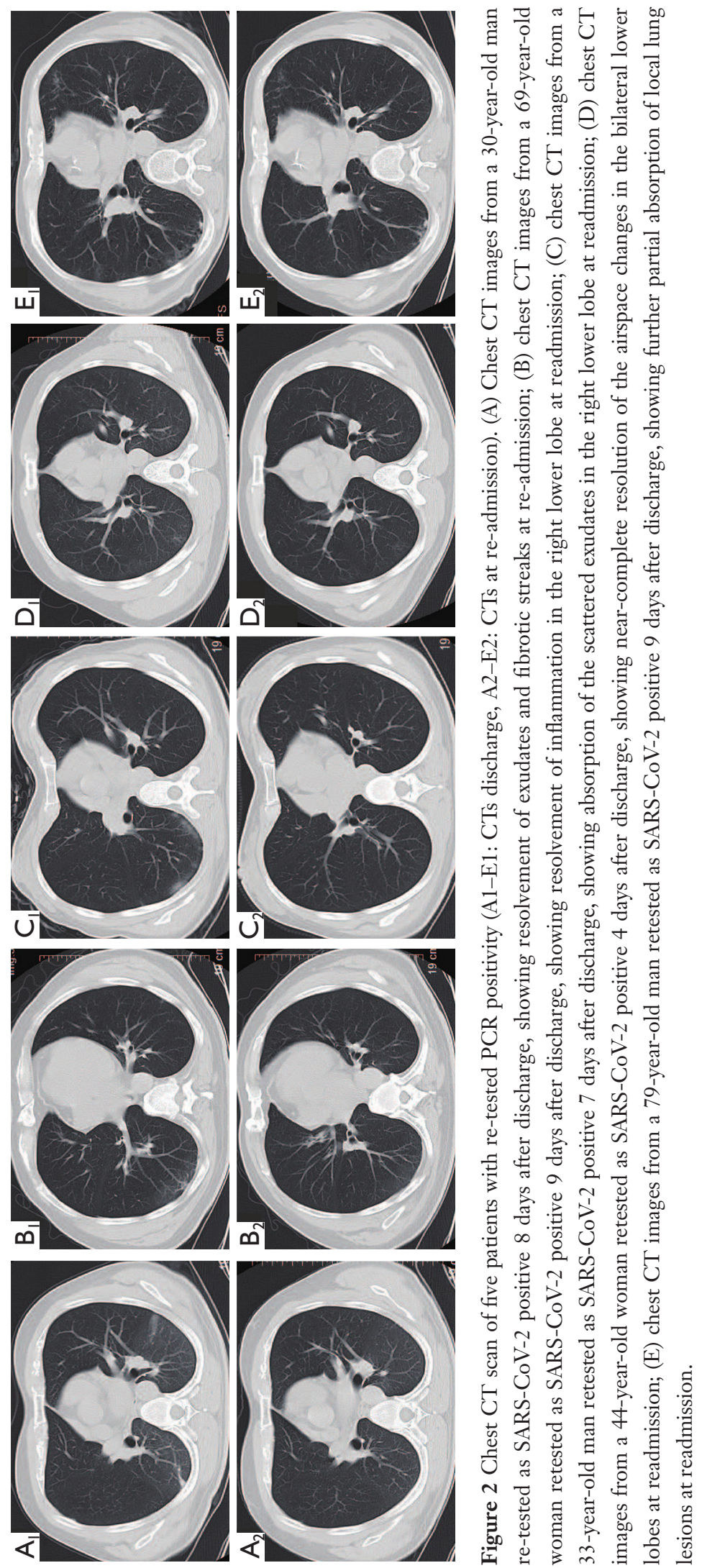
inflammations further absorbed spontaneously, it may not be necessary to offer additional treatment for these patients.

\section{Acknowledgments}

This work was supported by Open Project of Guangdong Provincial Key Laboratory of Tropical Disease Research. We acknowledge the patients, staffs at Guangzhou Eighth People's Hospital.

Funding: None.

\section{Footnote}

Conflicts of Interest: All authors have completed the ICMJE uniform disclosure form (available at http://dx.doi. org/10.21037/qims-20-656). The authors have no conflicts of interest to declare.

Ethical Statement: This study was approved by the institutional ethics board of Guangzhou Eighth People's Hospital and the requirement for informed consent was waived by the ethics board.

Open Access Statement: This is an Open Access article distributed in accordance with the Creative Commons Attribution-NonCommercial-NoDerivs 4.0 International License (CC BY-NC-ND 4.0), which permits the noncommercial replication and distribution of the article with the strict proviso that no changes or edits are made and the original work is properly cited (including links to both the formal publication through the relevant DOI and the license). See: https://creativecommons.org/licenses/by-nc-nd/4.0/.

\section{References}

1. Lu R, Zhao X, Li J, Niu P, Yang B, Wu H, Wang W, Song H, Huang B, Zhu N, Bi Y, Ma X, Zhan F, Wang L, Hu T, Zhou H, Hu Z, Zhou W, Zhao L, Chen J, Meng Y, Wang

Cite this article as: Zheng J, Chen F, Han S, Zhou R, Li F, Liu H, Lu J, Wu X. Recovery of pneumonia in 27 discharged COVID-19 patients with positive virus detection. Quant Imaging Med Surg 2020;10(7):1572-1575. doi: 10.21037/qims20-656
J, Lin Y, Yuan J, Xie Z, Ma J, Liu WJ, Wang D, Xu W, Holmes EC, Gao GF, Wu G, Chen W, Shi W, Tan W.

Genomic characterisation and epidemiology of 2019 novel coronavirus: implications for virus origins and receptor binding. Lancet 2020;395:565-74.

2. World Health Organization. WHO coronavirus disease (COVID-19) dashboard. Available online: https://covid19. who.int/ (Accessed May 19, 2020).

3. Jiang M, Li Y, Han M, Wang Z, Zhang Y, Du X. Recurrent PCR positivity after hospital discharge of people with coronavirus disease 2019 (COVID-19). J Infect 2020. [Epub ahead of print]. doi: 10.1016/j.jinf.2020.03.024.

4. Lan L, Xu D, Ye G, Xia C, Wang S, Li Y, Xu H. Positive RT-PCR test results in patients recovered from COVID-19. JAMA 2020;323:1502-3.

5. Xing Y, Mo P, Xiao Y, Zhao O, Zhang Y, Wang F. Postdischarge surveillance and positive virus detection in two medical staff recovered from coronavirus disease 2019 (COVID-19), China, January to February 2020. Euro Surveill 2020;25:2000191.

6. Li C, Luo F, Xie L, Gao Y, Zhang N, Wu B. Chest CT study of fifteen COVID-19 patients with positive RT-PCR retest results after discharge. Quant Imaging Med Surg 2020;10:1318-24.

7. Wáng YXJ. CT suggests discharged Covid-19 patients who were retested RT-PCR positive again for SARSCoV-2 more likely had false negative RT-PCR tests before discharging. Quant Imaging Med Surg 2020;10:1396-400.

8. Tang X, Zhao S, He D, Yang L, Wang MH, Li Y, Mei S, Zou X. Positive RT-PCR tests among discharged COVID-19 patients in Shenzhen, China. Infect Control Hosp Epidemiol 2020. [Epub ahead of print]. doi:10.1017/ ice.2020.134.

9. China National Health Commission. Chinese Clinical Guidance for COVID-19 Pneumonia Diagnosis and Treatment (7th edition). 2020. Available online: http:// kjfy.meetingchina.org/msite/news/show/cn/3337.html (Accessed on May 25, 2020). 